\title{
A new method for analysing socio-ecological patterns of vulnerability
}

\author{
Marcel Kok • Matthias Lüdeke • Paul Lucas • \\ Till Sterzel · Carsten Walther · Peter Janssen · \\ Diana Sietz $\cdot$ Indra de Soysa
}

Received: 3 September 2014/Accepted: 8 December 2014/Published online: 1 January 2015

(C) The Author(s) 2014. This article is published with open access at Springerlink.com

\begin{abstract}
This paper presents a method for the analysis of socio-ecological patterns of vulnerability of people being at risk of losing their livelihoods as a consequence of global environmental change. This method fills a gap in methodologies for vulnerability analysis by providing generalizations of the factors that shape vulnerability in specific socio-ecological systems and showing their spatial occurrence. The proposed method consists of four steps that include both quantitative and qualitative analyses. To start, the socio-ecological system exposed to global environmental changes that will be studied needs to be determined. This could, for example, be farmers in drylands, urban populations in coastal areas and forest-dependent people in the tropics. Next, the core dimensions that shape vulnerability in the socio-ecological system of interest need to be defined. Subsequently, a set of spatially explicit indicators
\end{abstract}

Editor: Elena M. Bennett.

Electronic supplementary material The online version of this article (doi:10.1007/s10113-014-0746-1) contains supplementary material, which is available to authorized users.

M. Kok $(\square) \cdot$ P. Lucas · P. Janssen

PBL Netherlands Environmental Assessment Agency,

The Hague/Bilthoven, The Netherlands

e-mail: marcel.kok@pbl.nl

M. Lüdeke · T. Sterzel · C. Walther · D. Sietz

Potsdam Institute for Climate Impact Research,

Potsdam, Germany

D. Sietz

Wageningen University and Research, Wageningen,

The Netherlands

I. de Soysa

Norwegian University of Science and Technology (NTNU),

Trondheim, Norway that reflect these core dimensions is selected. Cluster analysis is used for grouping the indicator data. The clusters found, referred to as vulnerability profiles, describe different typical groupings of conditions and processes that create vulnerability in the socio-ecological system under study, and their spatial distribution is provided. Interpretation and verification of these profiles is the last step in the analysis. We illustrate the application of this method by analysing the patterns of vulnerability of (smallholder) farmers in drylands. We identify eight distinct vulnerability profiles in drylands that together provide a global overview of different processes taking place and sub-national detail of their distribution. By overlaying the spatial distribution of these profiles with specific outcome indicators such as conflict occurrence or migration, the method can also be used to understand these phenomena better. Analysis of vulnerability profiles will in a next step be used as a basis for identifying responses to reduce vulnerability, for example, to facilitate the transfer of best practices to reduce vulnerability between different places.

Keywords Vulnerability - Global environmental change · Patterns · Drylands · Indicator-based analyses · Adaptation

\section{Introduction}

Many situations of human vulnerability around the world share similar features in terms of drivers and processes that create them. Insights in these similarities emerge from studies on, for example, land-use change, desertification and deforestation, food insecurity, freshwater scarcity, which show that, in many cases, a small set of key mechanisms explain these situations (Geist and Lambin 2001, 2004; Rudel 2005, 2008; Misselhorn 2005; 
Srinivasan et al. 2012). Insight in these mechanisms is important for developing policy responses to reduce vulnerability and facilitate learning across places. In this paper, we present a method for systematically investigating these mechanisms across the globe within a given socioecological system in a quantitative and spatially explicit manner. This method results in the identification of typical patterns of vulnerability on a global spatial scale. We apply the method to analyse the vulnerability of farmers in drylands to show the potential of this method for identifying options to reduce vulnerability.

Although there are differences in the use of terminology (Wolf et al. 2012; Hinkel 2011; Rothman et al. 2014), most frameworks for vulnerability analysis discussed in the literature distinguish between three components: exposure, sensitivity and coping/adaptive capacity (Birkmann 2013a; Kasperson et al. 2005; Mc Carthy et al. 2001; Parry et al. 2007; Patt et al. 2009; Schröter et al. 2005; Turner et al. 2003). Factors determining vulnerability to diverse pressures can operate over different temporal and spatial scales and require taking the whole human-environment system into account (Vogel and O'Brien 2004). To capture these various aspects, vulnerability research applies a wide range of methods, stemming from various disciplinary backgrounds and operating on all scales (from local to global). While this great variety of methods and the lack of unified approaches indeed makes it difficult to compare the results of vulnerability studies between different parts of the world or amongst different groups in society (Alcamo et al. 2008; Hinkel 2009, 2011), some frameworks have been proposed to facilitate unified analysis (Birkmann 2013a; Carter et al. 2007; Schröter et al. 2005; Polsky et al. 2007; Turner et al. 2003).

One of the reasons that vulnerability studies are difficult to compare, relates to the different spatial scales on which they operate. Often, vulnerability analyses are local case studies that address the usually complex, context-specific situations that shape vulnerabilities of a particular group in a specific socio-ecological situation (e.g. Eakin 2005; Sietz et al. 2006; Sallu et al. 2010). The generalization of case studies and their relevance in similar situations elsewhere is always a difficult question. At the other end of the spectrum, global vulnerability assessments are based on aggregated data and rather crude assumptions about the underlying mechanisms being assessed. Even with increasingly finer spatial resolution of global and regional data sets, the question remains whether local specifics can be adequately represented and understood in a global context (Kasperson et al. 2005).

We argue in this paper that vulnerability analysis on an intermediate level of complexity and spatial extent, such as is proposed here in the form of patterns of vulnerability, is a useful addition to currently available methods for unifying vulnerability analysis, which range from local (e.g. Eakin 2005) to regional (O'Brien et al. 2004) and global (Schröter et al. 2005). Analysing patterns of vulnerability helps to systematize outcomes of case studies with regard to the general, functional processes that shape vulnerability. Furthermore, this analysis does provide both global overviews and sub-national detail on the spatial distribution of these patterns. These insights can be used as entry points for developing policy responses to reduce vulnerability in different locations in which similar vulnerability-creating mechanisms play a role and facilitate learning across places. Furthermore, it renders a useful basis for understanding specific impacts in vulnerable situations, such as the occurrence of conflicts, through for example an overlay analysis (Sterzel et al. 2014) or migration (Neumann et al. 2014).

This idea of analysing patterns of vulnerability originates from the fourth Global Environmental Outlook: Environment for Development (GEO-4) published by the United Nations Environment Programme (UNEP 2007). In a response to requests from governments to show how the environment provides challenges and opportunities for human development, UNEP gave the concept of vulnerability a central place. While GEO is a global assessment, its strong regional focus also required going beyond providing coarse global overviews or simple rankings of vulnerability, to find new ways to be sufficiently relevant for countries and regions. From the regional analysis of state and trends in the environment and its impacts on human well-being, seven problem areas were derived in which the vulnerability of people in specific socio-ecological systems was analysed by looking at the main vulnerability-creating processes (Jäger et al. 2007; p. 318; Kok and Jäger 2013). These problem areas included the urbanization of the coastal fringe, disturbing the fragile equilibrium in drylands and small island developing states. The analysis of the global dryland was further elaborated in a global study by Sietz et al. (2011), which identified the spatial distribution of different types of dryland vulnerability.

Building on this analysis, as well as on additional work on patterns of vulnerability in various ecological systems (see Kok et al. 2009), we here present a further elaborated method and apply it to analyse vulnerability of (smallholder) farmers in drylands to show its added value, the methodological issues involved and the insights that can be gained from this type of analysis for policy making. While this paper focuses on the method, related publications apply this method and elaborate in more detail patterns of vulnerability related to forest overexploitation, rapid urbanization in coastal areas (cf. chapter 4 and 6 in Kok et al. 2010) and use the identified patterns of vulnerability to analyse conflict in drylands (Sterzel et al. 2014). 


\section{Rationale for identifying patterns of vulnerability}

The above-mentioned three components of vulnerability (exposure, sensitivity and coping/adaptive capacity) vary considerably amongst individuals, different social groups and communities, making human vulnerability to environmental change inherently different for each community or individual. Consequently, vulnerability is the outcome of multiple stressors and multiple actors in multiple contexts that can occur at various spatial and time scales (De Sherbinin et al. 2007; Patt et al. 2009; Schröter et al. 2005; Turner et al. 2003; Vogel and O'Brien 2004). Vulnerability analysis needs to reflect these complex realities.

Comprehensive vulnerability analysis of specific socioecological systems could be provided either starting from single case studies or from global indicator-based studies or indices. The synthesis of single case studies towards a more comprehensive overview of vulnerability is often hampered by the diversity and incongruency in approaches employed in the case studies and differences in availability and quality of data. Global overviews are typically falling short in including potentially important local specificities. Between these extremes, the approach to identifying patterns of vulnerability on an intermediate level of complexity (of mechanisms and conditions) and spatial resolution is an attempt to find a compromise leading to a more comprehensive picture of the major factors involved. Needless to say, this also has to cope with a limited availability of potentially important placebased information on the scale considered (especially for more complex social indicators such as power, politics and voice).

From a formal point of view, state-of-the-art vulnerability assessments on higher spatial scales commonly have index-based outcomes, in which the detail of study is aggregated to one value for each place (Lonergan et al. 1999; Cutter et al. 2003; Kaly et al. 2004, Welle et al. 2013). If vulnerability is reduced to a single composite indicator (index), the richness and complexity of the processes that create and maintain vulnerability is lost, even more so on the large scales of analysis considered (cf. Barnett et al. 2008). That is why it is argued that disaggregated indices are more useful than a single index, as they provide richer information on the structure of vulnerability (Adger et al. 2004). However, this leaves the reader with a multitude of combinations of the disaggregated indices, which are not systematically interpreted by the analyst. The pattern approach, which we suggest in this paper, is the logical next step by asking: Can we identify typical combinations of disaggregated indicators and-in case yes-how can they be interpreted in terms of vulnerability-generating mechanisms? In doing so, we prevent that the resulting vulnerability mapping is obscured by the far-fetched aggregation, which is a consequence of working with indexes (cf. Preston et al. 2011).

An existing approach addressing a similar problem of providing generic overviews on an intermediate level is the 'syndrome approach'. This approach looks at nonsustainable patterns of interaction between people and the environment at a global level, and aims to unveil the dynamics behind them (Petschel-Held et al. 1999; Lüdeke et al. 2004; Manuel-Navarrete et al. 2007). This approach was based on the hypothesis that it is possible to identify a limited number of typical dynamic causeeffect relationships (syndromes) at an intermediate level of complexity that allows to subsume case studies that address relevant environmental problems all over the globe. Srinivasan et al. (2012) recently present an interesting example of analysing and linking 22 humanwater system case studies over the globe in terms of a limited number of syndrome configurations. The resulting six syndromes can be explained by a limited set of causal factors falling into four categories: demand changes, supply changes, governance systems, and infrastructure and technology.

While the syndrome approach can be used for analysing separate local and regional case studies, it can also be applied to provide a global mapping, as exemplified in Cassel-Gintz et al. (1997) and Lüdeke et al. (2004) who semi-quantitatively assess the presence of non-sustainable development paths by employing fuzzy calculation rules on the basis of globally available indicator-information on factors of interest. This requires a set-up in which the various factors of interest are explicitly hypothesized to affect vulnerability of human well-being towards global and environmental change in a certain prescribed way, as represented by the (semi-quantitative) relationships employed. An interesting example of a related approach that explicitly postulates a framework to express vulnerability from various (disciplinary) viewpoints, and which also uses fuzzy indicators and calculation rules to build the associated inference models, is delivered by Alcamo et al. (2008, 2009).

In our approach, we employ a different way to analyse the vulnerability pattern within a well-defined socio-ecological system (e.g. agriculture in drylands). We do not impose a hypothesized predefined relationship, but let the available data on vulnerability mechanisms tell their own story: exploring the structure in the data-space we hope to (inductively) obtain clues on the underlying vulnerability patterns in a specific socio-ecological system worldwide, which can be presented on a global map. 


\section{Method for analysing patterns of vulnerability}

For analysing patterns of vulnerability within a chosen socio-ecological system, it is necessary to answer the following questions:

1. What are the main exposures, key vulnerable groups, their sensitivities and their coping and adaptive capacities?

2. What are the core dimensions of the patterns of vulnerability occurring in the socio-ecological system under investigation?

3. In which regions do we find similar vulnerability characteristics (vulnerability profiles)?

4. What do the different vulnerability profiles signify in terms of vulnerability-creating processes?

We propose a method to answer these questions in four steps that will be further elaborated below. It follows a similar logic as the framework of Schröter et al. (2005) for place-based studies. To be able to capture the various relevant dimensions of human vulnerability, we stress the need to combine qualitative analysis and quantitative tools in applying this method to identify and describe patterns of vulnerability. This needs to be an iterative process as each step provides knowledge that could require the analysis to go back to previous steps. The method offers also opportunities to involve different stakeholders in the analysis.

Step 1 Defining a relevant and distinct socio-ecological system for vulnerability analysis

\section{Question: What are the main exposures, key vulnerable groups, their sensitivities and coping and adaptive capacities in a specific socio-ecological system?}

There is no unique or objective way to identify relevant problem areas and socio-ecological systems. Different approaches that could be used are as follows: expertbased, like with the syndrome approach (WBGU 1995); user-driven, such as in the GEO process (Kok and Jäger (eds) 2009); or through science-policy workshops (Manuel-Navarrete et al. 2007). User-driven approaches will score better in terms of legitimacy of outcomes, while expert-driven identification may be biased, but efficient in terms of covering the present state of scientific knowledge.

The definition of a relevant problem area and a related socio-ecological system includes an identification of possible exposures, sensitivities and coping and/or adaptation mechanisms, and understanding how well-being of the vulnerable populations may be affected.
Step 2 Identification of core dimensions and indicators

Question: What are the core dimensions of the patterns of vulnerability occurring in the investigated socioecological system?

To further specify the socio-ecological system, the variety of mechanisms and processes constituting the vulnerability identified in the previous step needs to be reduced to what we label its 'core dimensions'. This can be done either by referring to existing literature on case study generalisations or by own vulnerability study generalisations, using, for example, the results of meta-analyses (Geist and Lambin 2001, 2004; Rudel 2005, 2008) or vulnerability scoping diagram (Polsky et al. 2007) to facilitate the comparison of assessments.

Next, indicators need to be identified that render information on the most important dimensions of the vulnerability-creating mechanisms. In principle, these indicators can be taken from all kinds of sources, e.g. survey data, model results, maps (Birkmann 2007, 2013b). As we want to understand where the patterns of vulnerability are occurring, this requires spatially explicit data as much as possible.

Step 3 Identification of vulnerability profiles and their spatial distribution

Question: In which regions do we find similar vulnerability profiles/situations?

To further answer the question in what form and where typical combinations of the vulnerability-creating processes occur, the selected indicators are subjected to formal data analysis. The outcomes of this step characterize the pattern of vulnerability in two components: (1) a functional component, which are specific constellations of indicators that we label 'vulnerability profiles' (see Fig. 1); and (2) a spatial component, which is the spatial distribution of the vulnerability profiles (see Fig. 2).

Several techniques for spatial data analysis exist (see Locantore et al. 2004 for an overview). When prior information on the inherent structure of data (in this case the indicator data) is absent or minimal as is usually the case with indicators used at a global level, cluster analysis is a suitable statistical technique to explore such data sets. It groups data into classes-groups or clusters-that share similar characteristics. Here, we use cluster analysis to identify specific constellations, or groups, of indicator values that suggest the different forms in which a pattern of vulnerability can manifest itself.

An important issue when carrying out cluster analysis is the decision on the number of clusters to be distinguished and 
used in the further analysis. To determine the number of clusters which provides an adequate representation of the internal structure of the data, we developed a measure of the stability of the cluster partitions. See Supplementary material for further details on the clustering method applied.

Step 4 Interpretation and verification of vulnerability profiles

Question: What do the different vulnerability profiles signify in terms of vulnerability-creating processes?

The distinct vulnerability profiles resulting from step 3 show typical indicator combinations. Relating this information to the core vulnerability dimensions of the considered socio-ecological system identified in step 2, each vulnerability profile has to be interpreted regarding the characteristic vulnerability-generating processes or mechanisms. The spatial distribution of these profiles around the world describes where these different manifestations can be found.

In this interpretation step, we analyse what drives the vulnerability for a specific cluster, what explains the differences between vulnerability profiles and whether the locations where a specific vulnerability profile occurs are also observed in reality. To verify the obtained results and interpretations, our quantitative analysis needs to be complemented with empirical, 'on the ground' information. This step is important to complement the global, quantitative data with local, 'on the ground' qualitative information (to address concerns raised by for example Carr and Kettle (2009) to adequately reflect conditions on the ground in quantitative global approaches). This can be done by comparing these outcomes with a meta-analysis of case studies or with numerous detailed case studies (see Sietz et al. 2011; Sietz 2014). We refer to this part of the analysis as 'ground-truthing', that is, relating the global, quantitative analysis to detailed information that is collected on the ground. This step adds meaning and detail to the analysis that cannot be derived directly from the global analysis and in this way helps to link the global analysis to local realities and thus supports the identification and interpretation of the vulnerability profiles.

\section{Patterns of vulnerability amongst farmers in drylands}

In this section, we illustrate the suggested general approach by its application to the socio-ecological system of dryland farming. The analysis shown here is a further development of prior studies of this problem area (Jäger et al. 2007; Kok et al. 2009; Sietz et al. 2011).
Step 1: Defining a relevant and distinct socio-ecological system for vulnerability analysis

Drylands are critical areas with respect to the challenges and trade-offs of improving human development in a fragile environment, with limited natural resources and high risks of overexploitation. Drylands are characterized by low rainfall and high rates of evaporation, occupy $41 \%$ of the Earth's land area and are home to half of all people living in poverty (Dobie 2001). Infant mortality rates in drylands in developing countries are relatively high. Most dryland developing countries have a large proportion of their labour force working in the agricultural sector, with smallholder farmers being highly dependent on natural capital and ecosystem services. Land degradation and climate change endanger agricultural production and environmental sustainability.

Step 2: Identification of core dimensions and indicators

Current literature (Geist and Lambin 2004; Reynolds et al. 2007; Safriel et al. 2005; Safriel and Adeel 2008) suggests that there are typical and common mechanisms at work that establish the vulnerability of smallholder farmers in dryland areas, especially in developing countries. Their vulnerability is characterized by increasing pressures on the natural resources from a growing population, limited and insecure access to water and fertile soils, and soil degradation resulting from overuse, combined with the breakdown of traditional coping mechanisms, barriers to alternative livelihoods and consequently threatened human. Poor infrastructure impedes market access and, thus, the ability to obtain inputs to enhance agricultural productivity and possibilities for selling products. All these factors may lead to situations in which rural households become enmeshed in poverty traps.

Major vulnerability-generating processes are summarised by Reynolds and colleagues (Reynolds et al. 2007) into five key variables important for the 'Dryland Development Paradigm', comprising high variability in rainfall (typically occurring in low precipitation areas), low soil fertility (small amounts of organic matter imply that tillage and grazing can quickly have major impacts), sparse populations (not in contradiction to high relative population growth), remoteness (e.g. from markets) and distant voice and remote governance (spatial and social distance from the centres and priorities of decision-making). As a result, Reynolds and colleagues show that dryland populations tend to lag behind populations in other parts of the world in terms of a variety of economic and health indicators with higher infant mortality, severe shortages of drinking water and much lower per capita incomes. 
The 'Dryland Livelihood Paradigm' (DLP) further refines the 'Dryland Development Paradigm' taking into account specifically the poverty-degradation spiral (Safriel and Adeel 2008). The DLP suggests two major alternative development paths. The first path encompasses two branches. One branch describes the overuse of natural resources driven by demographic and socio-economic stimuli leading into poverty, conflicts and violence. The other branch shows that even the sustainable use of resources may result in low human well-being due to the inherent marginality, ultimately inducing the same adverse effects on human well-being as shown in the former branch. In contrast, the second path involves also social and technological ingenuity that stimulates innovations and sustainable use of resources and/or transition to alternative, land-independent livelihoods which altogether stimulate sustainable development (see also Mortimore 2009).

On the basis of this analysis, we identify five core dimensions that describe the patterns of vulnerability in drylands. In this description of vulnerability human wellbeing is dependent on available natural resources (soils and water), that may be negatively influenced by pressures on resources, and their potential overuse, resulting in degradation (Dregne 2002). The latter creates a negative feedback on agricultural production and income generation (e.g. Safriel and Adeel 2008), while connectedness illustrates dependence of income generation on "soft and hard infrastructure" (e.g. Shiferaw et al. 2008), which-together with the available capital-also influences the improvement of agricultural techniques (Thomas 2008; Twomlow et al. 1999).

To describe these core dimensions, we have selected a set of seven global indicators (see Table 1). Pragmatic reasons as availability and quality of information for global (drylands) coverage and sub-national resolution have played a role in the ultimate choice of the indicators. As we intend to develop this method further in future work for the analysis of alternative scenarios, we have opted to use indicators derived from integrated assessment models, i.e. environmental indicators are related to the IMAGE model (MNP 2006; Stehfest et al. 2014), and indicators on human well-being and development are related to the GISMO model (Hilderink and Lucas 2008).

As a component of Human Well-being, income allows farmers to fulfil their needs and acquiring production enhancers. As for income no gridded data are available, we use country-level income data for all grid-cells within a specific country, supplemented with the infant mortality rate on the sub-national scale, as a proxy that gives some insight into the distribution of income. In case of a sufficient national average of GDP per capita, a high infant mortality rate suggests a very unequal distribution. With respect to natural resources, soil quality and climate conditions can be directly indicated by measuring agropotential. For this we use productivity of grassland compared to the maximum feasible natural productivity in perfect circumstances as a proxy. Furthermore, water availability is indicated by the water run-off per river basin. Pressure on these natural resources is indicated by the population density. To indicate overuse, we use water erosion, which is the most important cause for soil degradation around the world, represented by the water erosion index, i.e. the sensitivity to water erosion in a qualitative sense. Finally, connectedness or access to soft and hard infrastructures is indicated by infrastructure density, which is total length of roads per square kilometre.

Step 3: Identification of vulnerability profiles and their spatial distribution

This step identifies in which areas we find similar vulnerability profiles. Cluster analysis is used to identify typical

Table 1 Core dimensions addressed, main variables and indicators and proxies used

\begin{tabular}{|c|c|c|c|c|}
\hline Core dimension & Variable & Indicator & Proxy & Source \\
\hline \multirow[t]{2}{*}{$\begin{array}{l}\text { Human well- } \\
\text { being }\end{array}$} & Income & Average per capita income & GDP per capita & $\begin{array}{l}\text { (UNSTAT, 2005; World } \\
\text { Bank, 2006) }\end{array}$ \\
\hline & $\begin{array}{l}\text { Distribution of } \\
\text { income }\end{array}$ & Infant mortality & Infant mortality rate & (CIESIN, 2005) \\
\hline $\begin{array}{l}\text { Pressure on } \\
\text { resources }\end{array}$ & Demand for water & Population density & Population density & $\begin{array}{l}\text { (Klein Goldewijk, et al., } \\
\text { 2010) }\end{array}$ \\
\hline Connectedness & $\begin{array}{l}\text { Soft and hard } \\
\text { infrastructure }\end{array}$ & Infrastructure density & Road density & $\begin{array}{l}\text { (Meijer and Klein } \\
\text { Goldewijk, 2009) }\end{array}$ \\
\hline \multirow{2}{*}{$\begin{array}{l}\text { Natural } \\
\text { resources }\end{array}$} & Water supply & Renewable water resource & Surface run-off & (Alcamo et al., 2000) \\
\hline & Soil quality & Agro-potential & $\begin{array}{l}\text { Productivity of grassland compared to the } \\
\text { max feasible }\end{array}$ & (MNP, 2006) \\
\hline Overuse & Soil overuse & $\begin{array}{l}\text { Soil erosion (through water } \\
\text { erosion) }\end{array}$ & Water erosion index & (Hootsman et al., 2001) \\
\hline
\end{tabular}


indicator value combinations in the multiple indicator dataspace. The optimum number of clusters is determined by investigating the stability of calculated cluster partitions under different initial conditions (see Supplementary material, Figure S1a). The absolute maximum is for three clusters, which mainly shows a divide between developing countries and developed countries; a plausible result that, however, does not add much new information to our understanding. A richer interpretation comes from the relative maximum at eight clusters, which hints at an inherent property of the structure in the indicator space. However, even not exactly knowing the optimum number of clusters would not be a severe problem in this case, as the 'branching diagram' in Supplementary material (Figure S1b) shows. This diagram suggests how clusters split up or merge when increasing or decreasing the number of clusters considered. Using a smaller cluster number than eight implies that the picture becomes less differentiated, i.e. clusters are mainly merged by going to smaller cluster numbers.

At this point, the question may arise as to whether or not there is a ranking in the importance of single indicators in generating the cluster separation. The 'Fraiman measure' as depicted in Supplementary material (Figure S1c) shows that the average income is the most important variable for cluster separation, followed by agro-potential and soil erosion; infant mortality and water availability have still some importance. Even though the ranking is led by an economic variable, it is an almost equal mixture of socioeconomic variables, natural conditions and variables that all characterize the intensity of resource usage.
The eight clusters define different typical vulnerability profiles, i.e. combinations of indicator values that characterize specific vulnerabilities in different dryland areas (see Fig. 1). Although these vulnerability profiles are characterized by the (normalized) cluster centres, there can be significant variation for specific indicators around these average values that can be helpful in characterizing and interpreting these clusters in terms of specific features of the variables considered. Box-plots serve this purpose as they indicate next to the cluster centres also high and low percentiles of the data (see Supplementary material, Figure S1d), with a small spread indicating that these indicators are relatively distinctive when comparing various clusters. The spatial distribution of these profiles is provided in Fig. 2, which clearly shows that six of the vulnerability profiles relate to drylands in developing countries.

Step 4: Interpretation and verification of vulnerability profiles

In this step, the vulnerability profiles are interpreted and their plausibility is tested in comparison with other related information, as, for example, independent global maps, single local case studies falling spatially within a specific cluster area and meta-analyses. This leads to better understanding of the processes hypothesized by the profiles and to partial verification of their spatial distribution.

The two developed clusters (dark lilac-marginal and bright lilac-less marginal in Figs. 1 and 2) occur in industrialised countries and show high values for average income

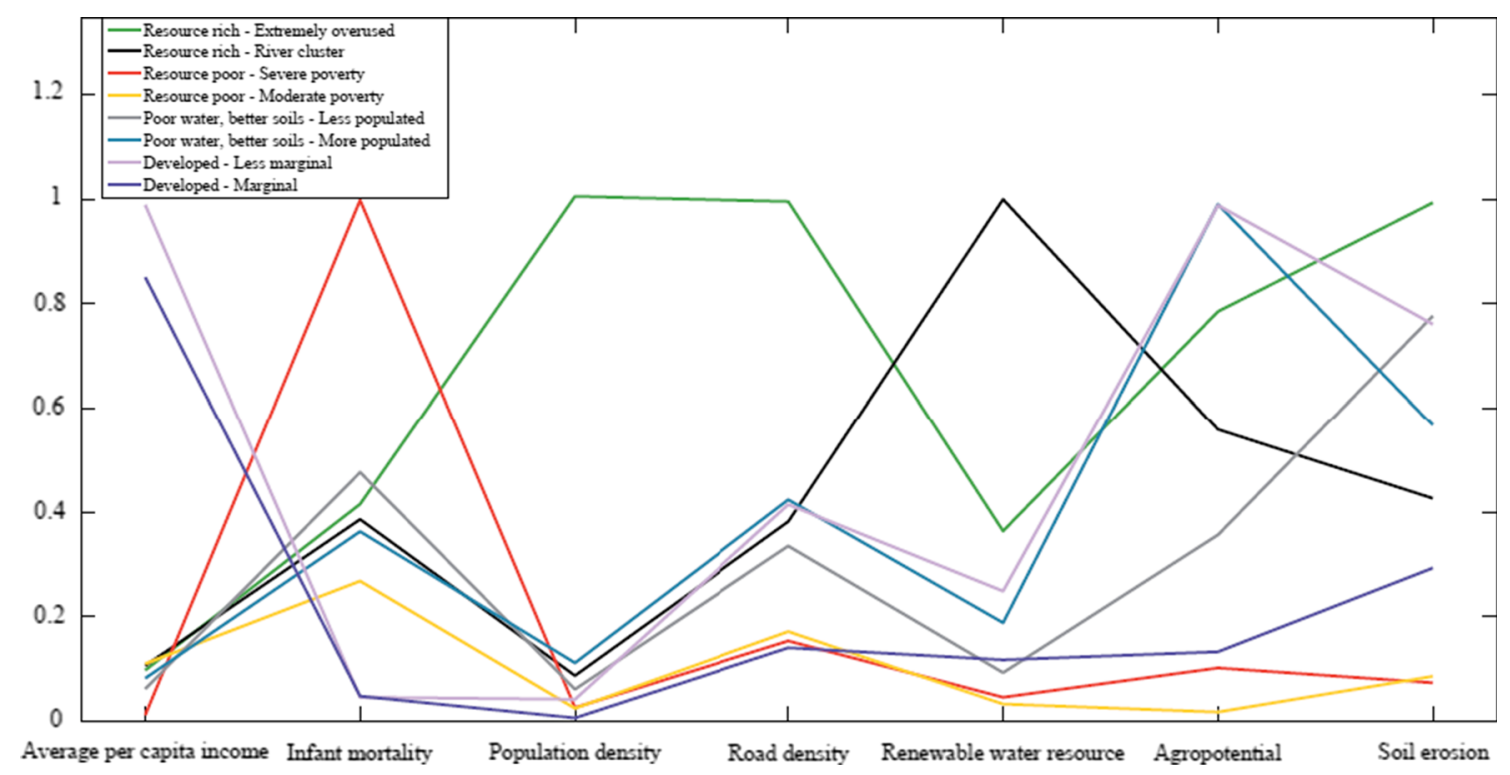

Fig. 1 Eight typical vulnerability profiles in drylands worldwide. The lines show the average indicator values (i.e. the cluster centres) of the respective cluster. These average indicator values have been normalized between 0 and 1 using their minimum and maximum values over the different clusters and thus show relative differences of the average indicator scores rather than their absolute differences. The line colours match the colours used in Fig. 2 depicting the geographical distribution of the clusters 


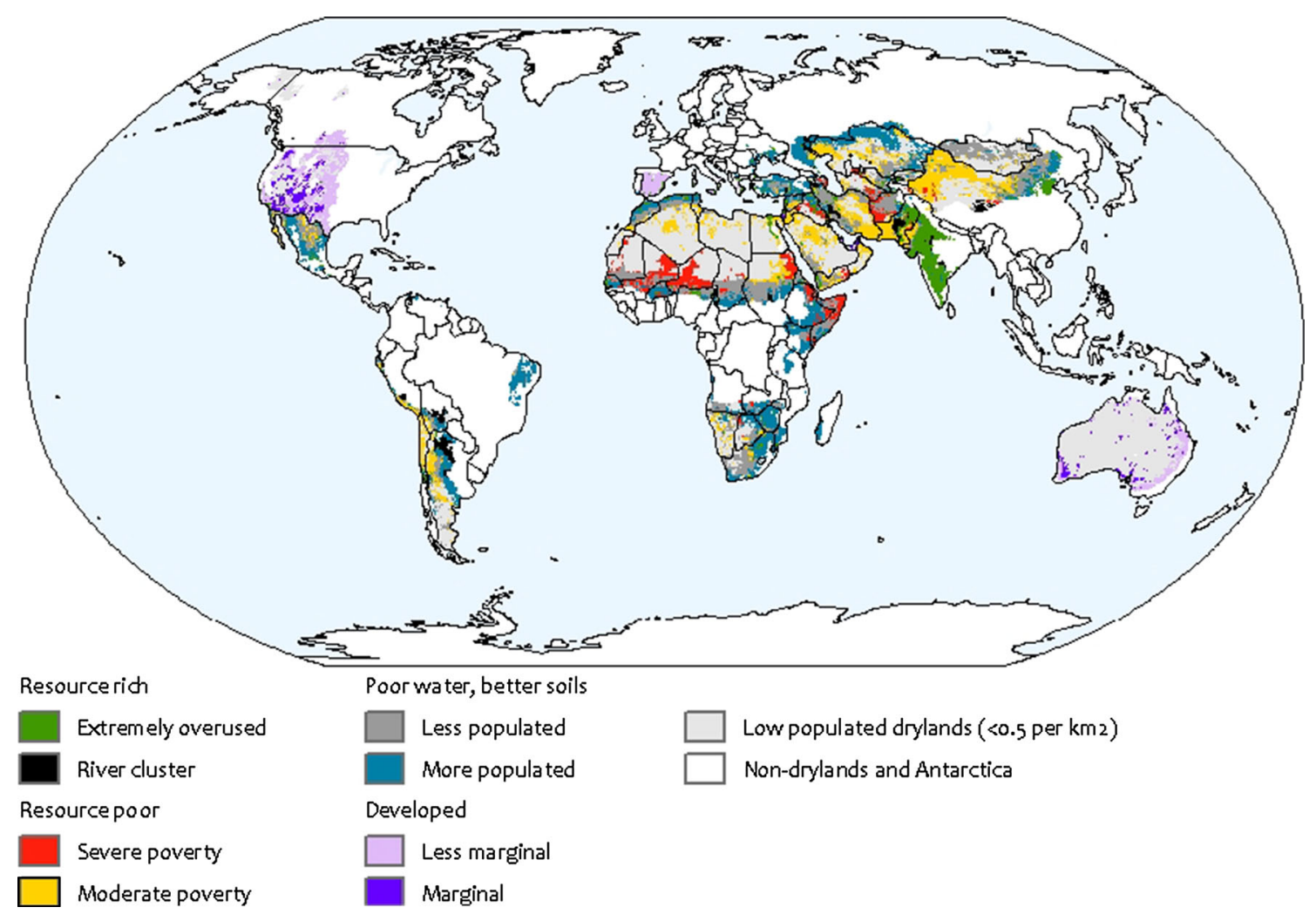

Fig. 2 Distribution of the eight vulnerability profiles for farmers in drylands worldwide. If, for example, droughts increase, dryland farmers in these different areas become more vulnerable for different reasons. For the respective vulnerability profiles see Fig. 1. Low-

and very low infant mortalities. The main difference between the two clusters lies in the difference in agropotential (factor 7), which might be linked to higher values of road (factor 3 ) and population (factor 7) density in the less marginal developed cluster (see bright lilac line in Fig. 1). In addition to the better agro-potential, the amount of available water is also higher, both of which could motivate more intensive agriculture that potentially generates significant soil erosion. The dark lilac-marginal cluster with agro-potential and amount of available water worse than the bright lilac-less marginal cluster, has only $14 \%$ of the population density compared with the bright lilac wealthy cluster, and related to that, a lower road density. Nevertheless, it still has a noticeable soil erosion rate, suggesting soil overuse. Both clusters and their separation are rather robust as their box-plots (Figure S1d) show relatively small variation for most indicators and those indicators that distinguish their partition most show only little overlap when comparing both clusters. With respect to their geographical distribution, these two clusters comprise the arid areas of the OECD countries-according to the dryland definition used here-mainly in the US, Spain, Italy and Australia. Comparison with maps on irrigated cropland (Siebert et al. 2005) populated dryland areas (less 0.5 per $\mathrm{km}^{2}$ ) have been excluded for analysis since representative indicator information on the humanenvironment interaction for these areas is less reliable

and livestock production systems (FAO 2006) shows that the significant soil erosion of the bright lilac cluster correlates with a high percentage of irrigated cropland, whereas the somewhat lower erosion in the dark lilac cluster is mainly associated to overgrazing. Comparison of these cluster results with the meta-analysis study on dryland degradation (desertification) by Geist and Lambin (2004) may serve as an example of verification. From the systematic evaluation of a large number of case studies on desertification processes all over the world, they concluded that for Europe most of the case studies report agricultural activities as proximate cause for dryland degradation (share of cropping: $77 \%$ ). For Europe, the cluster analysis identifies almost exclusively the bright lilac cluster where high soil degradation is related to intense crop farming which fits the Geist and Lambin findings. Furthermore they obtain for the USA and Australia that the majority of the case studies report agricultural activities as proximate cause, but here livestock dominates with $83 \%$ over cropping with $17 \%$ (USA) or has an equal share (Australia). The cluster analysis reproduces this observed situation by identifying a mixture of the bright lilac and dark lilac clusters for both countries, the latter indicating the less fertile and overused rangelands. 
The resource-poor vulnerability profiles (red and yellow in Figs. 1 and 2) identify the most resource-constrained and isolated areas of the world, indicated by the lowest renewable water resources and agro-potential. The harsh dryland conditions might explain the still relatively low levels of soil degradation, as agricultural and grazing practices are not favoured. The very limited renewable water resources pose the risk of unreliable supply. The two profiles differ mainly in level of human well-being (income and infant mortality). Also here, both clusters and their separation are rather robust. Their box-plots (Figure S1d) show very small variation for the indicators, and the infant mortality rate, the most distinct indicator for the two clusters, shows no overlap for the 5th-95th percentiles. Severe poverty occurs in areas dominated by pastoral land use (red cluster: GDP/cap: $11 \%$, Infant Mortality Rate: factor 4 compared to the yellow cluster). This cluster is, e.g. identified in Somalia, described by a case study of Le Sage and Majid (2002). In this region, despite some improvements in access to natural resources and security, the ability of people to recover and stabilize their livelihoods is very limited. The poorest people there are not able to benefit from occasionally better rainfall due to the depleted asset base and war-related constraints to access productive resources. Even though better situated people may produce more crops, debt repayment and recurrent droughts continue to exhaust their livelihood assets. In the yellow cluster, mainly located in the old world's dry belt, Mexico and the North of Chile/Argentina more moderate poverty occurs in zones between pastoral and sporadic, sparse forms of agriculture on the desert fringes and in areas where national economies allow for improved living conditions, for example, because of fossil-fuel exploitation in northern Africa and Saudi Arabia.

The poor water, better soils vulnerability profiles (grey and blue in Figs. 1 and 2) are less agro-constrained, indicated by medium to high agro-potential, and high soil degradation. The two clusters differ mainly in agricultural conditions and population density which is twice as large for the blue cluster. This is a small absolute difference which, however, is important: more favourable agricultural conditions are combined with proportionally higher population densities, while poverty levels are similar, as expressed by infant mortality levels. For both clusters, the box-plots (Figure S1d) show small to medium variation for the indicators (width of $50 \%$-box around the median from 0.08 to 0.3 ). Furthermore, except for the agro-potential, the 5-95th percentiles largely overlap for the two clusters. This makes agro-potential the most important single indicator to distinguish these two clusters. The two vulnerability patterns are found in parallel areas, e.g. neighbouring deserts and the less-populated areas close to the desert. The blue cluster is identified for rural areas of East Ethiopia and the
Makueni District in Southern Kenia. For both regions, detailed case studies exist which can be used for validation. According to Kassahun et al. (2008), rangeland degradation in East Ethiopia has increased in severity and magnitude since the 1970s, resulting in widespread erosion, compaction and salinization of soils. Overgrazing and overexploitation of woody plants further accelerate the pace of soil degradation. Water bodies were also affected by agricultural activities. In the past, rivers were increasingly diverted, which resulted in diminished accessibility in water resources for domestic use and livestock production. This ongoing overuse of natural resources induces declining agricultural yields and generates conflicts over grazing areas and water resources. As a result, food insecurity and increased poverty is observed. This case reflects the overuse of an acceptable agro-potential by an increasing population resulting in poor human well-being as described by the blue vulnerability profile. The same holds for Makueni (Southern Kenia) where Ifejika Speranza et al. (2008) report the combination of low human well-being and high soil degradation under population pressures. Croplands in the Makueni district are heavily degraded since soil and water conservation measures are rarely applied. Together with the unreliable rainfall being characteristic for drylands and partly infertile soils, food production is difficult to be secured. The resulting food insecurity translates into a limited human well-being.

The resource rich vulnerability profiles (green and black in Figs. 1 and 2) are characterized by better natural conditions. Both vulnerability profiles are least agro-constrained (highest agropotential), while human well-being (average income and infant mortality) is comparable to the poor water, better soils profile. Here, soils have been extremely degraded by a very dense population, also putting future generations under increased pressure. This profile dominates the arid areas of India, but is also found in north-eastern China and on the African Mediterranean coast. A good illustration for the Indian occurrence of this cluster is the case study of Ram et al. (1999) describing the situation in Khabra Kalan (Rajasthan). It shows the relation of increasing population, shrinking land holdings and shortfall of food on small farms which results in the deterioration of the land productivity.

The river vulnerability profile (black) shows moderate agro-constraints and is best endowed with water resources. Furthermore, soil degradation here is moderate compared to the other patterns. This profile combines relatively high income levels with relatively high infant mortality compared to other developing countries, suggesting a very uneven distribution of income opportunities, probably due to differences in access to irrigation and grassland and services such as health and education. This is related to the distribution of income; the on average good natural 
resources may be distributed unequally amongst the population. For the Balochistan part of the Indus basin belonging to the black cluster, Mustafa and Qazi (2007) results agree with the conclusions drawn from the vulnerability profile by showing how the transition from a sustainable, traditional irrigation system ('karez') to groundwater pumping leads to increasing social disparities and degradation of environmental resources. This profile is found around the lower reaches of the Indus, Euphrates, Tigris and Volga rivers, and in other irrigation areas, such as around the Aral Sea. Both clusters show relatively large variation in their indicator values (Figure S1d), while for the indicators that are most characteristic for the two clusters (population density in the green cluster and renewable water resources in the black cluster) their 5 th to 95th percentiles almost do not overlap with the other clusters.

\section{Potential for using patterns of vulnerability for further analysis and policy applications}

Logical questions to ask at this point are what the added value of this approach is and how it can serve policy making in addressing and reducing vulnerability. Next to contributing to improved understanding of vulnerability in specific socio-ecological systems, we suggest that patterns of vulnerability can be used in at least three different ways: as a basis for identifying specific responses to reduce vulnerability; to identify opportunities for transferability of local approaches for reducing vulnerability to other places; and as a basis for overlay analysis with information on other issues to obtain novel insights on the possible interrelatedness of these issues with dimensions of vulnerability. We briefly elaborate these below.

\section{Basis for analysing response options}

Response options are usually either very place specific or identified at a generic level, see (GTZ 2009; Jäger et al. 2007; Mortimore 2009), for example, in drylands. But using the vulnerability profiles identified with the proposed method, specific places and contexts can be further related to response options. As illustration, we here elaborate cluster-specific policy options for some of the vulnerability profiles obtained for the dryland case in Section Patterns of vulnerability amongst farmers in drylands.

In the 'poor-water, better-soil' clusters, the soil degradation rate is relatively high and endangers future yields. This can be avoided by the implementation of more sustainable resource management options. For an extensive list of concrete measures see Dixon et al. (2001). The cluster results imply that the more critical resource situation in the grey cluster, reflected by almost solely pastoral use, leaves fewer possibilities to improve productivity by innovative agricultural techniques than in the better endowed blue cluster. This makes it less probable to improve human well-being for the existing population in the grey cluster on the basis of agricultural production. As a consequence, either non-agricultural offfarm labour has to be developed and/or provided. In the blue cluster with better agro-potential, the chance of improving quality of life by more sustainable resource management seems an interesting option, together with limited population density growth. In-migration from less endowed regions, such as the grey areas, could endanger this opportunity if the implication from the comparison of the poor water, better soils clusters holds that population density tends to increase until living conditions become unacceptable.

In the two resource-scarce clusters, the opportunities provided by the natural resource base are inherently very weak. Comparison of the red and yellow clusters reveals that, for the present population density, even a somewhat better agro-potential does not contribute to more wealth suggesting that other national economic conditions are much more important. So, assuming the cluster analysis catches the most relevant factors, moving away from agriculture as main source of income seems here to be the only economically and environmentally sustainable solution.

The same is the case for the overuse cluster. The critical state of intensive agricultural overuse that generates only a very small income from relatively good natural resources due to the high population density can hardly be stabilized by new agricultural practices only. At the same time, pressure on productivity here has to be reduced and ecosystem restoration becomes an option. The natural conditions would then turn into an opportunity for sustainable livelihoods.

\section{Transferability}

Patterns of vulnerability allow local policymakers to recognize their specific situation within a broader context of similar situations, providing regional perspectives and important connections between regions, as well as the global context. The method can in this way also be used to identify potential for transferability of policy interventions which were successful in one place to another location. This can be assessed on the basis of the vulnerability profiles, as they identify locations of similar context and problem structure suggesting a similar response to a particular intervention.

Herwig and Ludi (1999) compared the response of seven agricultural plots in the highlands of Ethiopia and Eritrea 
regarding their response to five different soil conservations measures. Three of these plots are located within the dryland mask, two belong to the grey cluster (poor water, better soils, less populated) and one to the blue cluster (poor water, better soils, more populated). One conservation measure ('grass strip') was tested in all three locations showing a clear difference in erosion reduction between the 'grey' cases $(-77 \pm 4 \%)$ and the 'blue' case $(-55 \%)$. Three further conservation measures showed significant responses and allowed for pairwise comparison of the two clusters, all resulting in a much stronger reduction in soil erosion rate for the grey cluster locations, in one case even a strong increase in erosion for the blue cluster location was observed. This is a hint that cluster membership is helpful to understand the success of mitigation measures that were helpful in some locations belonging to a specific cluster.

Given the limited amount of resources available to reduce vulnerability, the identification of similarities may provide additional information necessary for ensuring targeted and more effective interventions. In doing so one should, however, take care not to overlook local conditions and contexts which can be essential for improving the well-being for the vulnerable people involved (Tschakert 2007).

\section{Overlay analysis}

The question arises whether vulnerability profiles and their spatial distribution are useful for analysing other societal outcomes which the vulnerability-creating mechanisms can have implications for, yet are not included in the profiles. This question can be addressed by functionally and spatially relating the profiles to geo-referenced outcomes with established or conceivable links in the literature, such as violent conflicts (Sterzel et al. 2014). In this way, potential policy-relevant underlying causes or circumstances that support or reduce these outcomes can be identified or verified.

Aiming at testing this approach, Sterzel et al. (2014) investigated to what extent the typical profiles of the natural and socio-economic factors that characterize the vulnerability of drylands population to global environmental change presented in this paper are also relevant for explaining the spatial distribution and proneness of violent conflicts of the respective socio-ecological system. They found that conflict incidence in global drylands is heterogeneously concentrated according to the identified typical profiles of socio-ecological vulnerability. Then they show why this intrinsically nonlinear approach displays measurable added value over commonly used mono- and multivariate regression model-fits for explaining conflict distribution and proneness in a specific area.

\section{Discussion and conclusions}

In this paper, we have presented a method for identifying typical patterns of vulnerability within a given socio-ecological system. Furthermore, we have illustrated the use of the method by analysing the patterns of vulnerability of farmers in drylands, providing a global overview and subnational detail. We have also provided how this method could be used for further analysis and policy application.

The core of the method is an indicator-based analysis of a specific socio-ecological system. Cluster analysis is used for analysing indicator data and complemented with verification using (meta-analysis of) available independent case studies and maps. The resulting clusters are distinct and robust combinations of indicator values which are referred to as vulnerability profiles. Vulnerability profiles could be interpreted in terms of the main vulnerabilitycreating processes that make people in specific situations vulnerable. Furthermore, the cluster partitioning algorithm pinpoints these clusters to specific locations (spatial distribution) and thereby shows where specific appearances of a pattern of vulnerability take place. The vulnerability profiles provide an entry point for identifying opportunities to reduce vulnerability and directions for policy making. Positioning our method into the framework suggested by Schröter et al. (2005), it is clear that for materializing our method, we have to build on insights - concerning core dimensions and vulnerability mechanisms of interestobtained from place-based vulnerability studies performed by others. With a view on furthering the 'public good' of additional insights through cross-study comparisons of research projects designed with common principles, it is clear that the methodological steps in our method are very much aligned to those presented in Schröter et al. (2005).

As the method is not only used to analyse drylands, but also to analyse patterns of vulnerability in relation to 'rapid urbanization in coastal areas' and other socio-ecological systems such as over-exploitation of tropical forest (see chapter 4 and 6 in Kok et al. 2010), we suggest that this new method can provide relevant insights to various human-environment systems where 'specific, representative patterns of the interactions between environmental change and human well-being' are occurring. This does not need to be restricted to global overviews, but may also be applied on a regional or country level. This would also increase opportunities to involve stakeholders in the analysis (for a first attempt see Sietz et al. 2012).

Reflecting scale-dependent opportunities, working at the global level limits verification efforts due to constraints in globally available observational data. Global data sets should therefore be further developed to provide data which reflect well the spatial and temporal differences in vulnerability outcomes in order to support a more rigorous 
validation for this type of study. In contrast, applying the method at the local level might facilitate to verify outcomebased aspects of the vulnerability profiles due to better data availability. For example, a study of smallholders' vulnerability in the Peruvian Andes shows the clear correlation between the identified patterns of vulnerability and an independent data set of reported differential vulnerability outcomes in a post-event situation. This relation highlights the relevance of the identified clusters for decision-making processes (Sietz et al. 2012). This kind of verification complements studies that test the consistency of indices of vulnerability against independent data sets of observed or perceived vulnerability outcomes (e.g. this study, Alcamo et al. 2008; Fekete 2009).

A number of considerations need, however, to be taken into account in applying and further developing this method:

- Data requirements may form an impediment to applying this method (indicator selection and verification of results), as global indicator data are not always available for all the processes that constitute a pattern of vulnerability. This is especially the case for socioeconomic indicators such as power, politics and voice that are often at the root of communities' vulnerabilities.

- In addition to indicator selection, stakeholder involvement may help explain important causes for differences in underlying processes to support the interpretation and verification of the vulnerability patterns. For example, smallholders reported causes of climate vulnerability, which deliver rich details that verify and improve the understanding of particular mechanisms in the local context of the Peruvian Andes (Sietz et al. 2012).

- To be able to link vulnerability profiles to the identification of possible policy responses, further meta-analysis of case studies is necessary that establishes the link between vulnerability profiles and the portfolio of opportunities and policy options, their comparability and the possibilities of transferability in a way that also adequately reflect local to regional heterogeneity. One way forward is to link global vulnerability patterns in a spatially explicit way with regionally relevant processes such as shown by an integrated assessment that refines global insights and related options to reduce smallholder vulnerability in Northeast Brazil by combining cluster-based and dynamic modelling approaches (Sietz 2014).

- Application of this method does not directly render information whether certain clusters are more vulnerable than other clusters. Still, to get some insights into how vulnerable a certain cluster is, different rankings of the clusters on single indicator values can provide additional insights on relative risks. Here overlay analysis can be useful, as is indicated by the overlay of the dryland analysis with conflict data by Sterzel et al. (2014) because data with poor spatial coverage can be related in the study afterwards and complement the picture of vulnerability obtained thus far.

- The consequences of alternative policy scenarios for vulnerable groups can be analysed, using global integrated assessment models. This would require extending the cluster analysis into the future by using scenario data from these models (see Lüdeke et al. 2014 for an initial attempt to explore this idea further).

The proposed method for analysing patterns of vulnerability contributes to a better understanding of important processes that constitute risks in similar situations. It shows the spatial distribution of these patterns at the sub-national level, due to the use of geographically explicit indicators. Moreover it can be helpful in strategic thinking about opportunities, responses and policies to reduce vulnerability. Insight into these basic processes that constitute risks can help decision-making to set priorities how to reduce vulnerability and enhance development efforts.

Acknowledgments We thank Henk Hilderink, Jill Jäger and Jenny Ordonez and three anonymous reviewers for comments on earlier drafts of this paper.

Open Access This article is distributed under the terms of the Creative Commons Attribution License which permits any use, distribution, and reproduction in any medium, provided the original author(s) and the source are credited.

\section{References}

Adger WN, Brooks N, Bentham G, Agnew M, Eriksen S (2004) New indicators of vulnerability and adaptive capacity. Norwich, UK: Tyndall centre for climate change research. Available at: http:// www.tyndall.ac.uk/theme3/final_reports/it1_11.pdf

Alcamo J, Henrichs T, Rösch T (2000) World water in 2025-global modeling and scenario analysis for the world commission on water for the 21st Century. No. 2, University of Kassel

Alcamo J, Acosta-Michlik L, Carius A, Eierdanz F, Klein R, Krömker D, Tänzler D (2008) A new approach to quantifying and comparing vulnerability to drought. Reg Environ Change 8:137-149. doi:10.1007/s10113-008-0065-5

Alcamo J, Acosta-Michlik L, Carius A, Eierdanz F (2009) Reply to commentary of Carr and Kettle, the challenge of quantifying susceptibility to drought-related crisis. Reg Environ Change 9:137-138. doi:10.1007/s10113-009-0087-7

Barnett J, Lambert S, Fry I (2008) The hazards of indicators: insights from the environmental vulnerability index. Ann Assoc Am Geogr 98(1):102-111. doi:10.1080/00045600701734315

Ben-Hur A, Elisieeff A, Guyon I (2002) A stability based method for discovering structure in clustered data. Pac Symp Biocomput 2002:6-17 
Birkmann J (2007) Risk and vulnerability indicators at different scales: applicability, usefulness and policy implications. Environ Hazards 7:20-31. doi:10.1016/j.envhaz.2007.04.002

Birkmann J (2013a) Measuring vulnerability to promote disasterresilient societies and to enhance adaptation: conceptual frameworks, definitions. Chapter 1 in: Measuring vulnerability to natural hazards. Towards disaster resilient societies. Second edition. 2013. UNU press

Birkmann, J. (2013b). Data, indicators and criteria for measuring vulnerability: theoretical bases and requirements. Chapter 2 in: measuring vulnerability to natural hazards. Towards disaster resilient societies. Second edition. 2013. UNU press

Carr ER, Kettle NP (2009) Commentary: the challenge of quantifying susceptibility to drought-related crisis. Reg Environ Change 9:131-136. doi:10.1007/s10113-009-0088-6

Carter TR, Jones RN, Lu X, Bhadwal S, Conde C, Mearns LO, O’Neill BC, Rounsevell MDA, Zurek MB (2007) New assessment methods and the characterisation of future conditions. In: Parry ML, Canziani OF, Palutikof JP, van der Linden PJ, Hanson CE (eds) Climate change 2007: impacts, adaptation and vulnerability. Contribution of working group II to the fourth assessment report of the intergovernmental panel on climate change. Cambridge University Press, Cambridge, pp 133-171

Cassel-Gintz M, Lüdeke MKB, Petschel-Held G, Reusswig F, Plöchl M, Lammel G, Schellnhuber HJ (1997) Fuzzy logic based global assessment of the marginality of agricultural land use. Clim Res 8(1997):135-150. doi:10.3354/cr008135

CIESIN (2005) Poverty mapping project: global subnational infant mortality rates, center for international earth science information network (CIESIN), socioeconomic data and applications center (SEDAC), Columbia University, Palisades, NY, Available at: http://sedac.ciesin.columbia.edu/povmap/

Cutter SL, Boruff BJ, Shirley WL (2003) Social vulnerability to environmental hazards. Soc Sci Q 84(2):242-261. doi:10.1111/ 1540-6237.8402002

De Sherbinin A, Schiller A, Pulpisher A (2007) The vulnerability of global cities to climate hazards. Environ Urban 19:39-64. doi:10.1177/0956247807076725

Dixon J, Gulliver A, Gibbon D (2001) Farming systems and poverty improving farmers' livelihoods in a changing world. FAO and World Bank, Rome and Washington DC

Dobie P (2001) Poverty and the drylands, United Nations Development Programme

Dregne HE (2002) Land degradation in the drylands. Arid Land Res Manag 16:99-132. doi:10.1080/153249802317304422

Eakin H (2005) Institutional change, climate risk and rural vulnerability: cases from Central Mexico. World Dev 33:1923-1938. doi:10.1016/j.worlddev.2005.06.005

Everitt BS, Landau S, Leese M (2001) Cluster analysis, 4th edn. London, Arnold Publishers

FAO (2006) Livestock's long shadow: environmental issues and options. Food and Agriculture Organisation of the United Nations, Rome

Fekete A (2009) Validation of a social vulnerability index in context to river-foods in Germany. Nat Hazards Earth Sys Sci 9:393-403. doi:10.5194/nhess-9-393-2009

Fraiman R, Justerl A, Svarc M (2008) Selection of variables for cluster analysis and classification rules. J Am Stat Assoc 103(483):1294-1303. doi:10.1198/016214508000000544

Geist HJ, Lambin EF (2001) What drives tropical deforestation? A meta-analysis of proximate and underlying causes of deforestation based on subnational case study evidence, LUCC report series $\mathrm{N}^{\circ} 4,83$ p. University of Louvain, Louvain-la-Neuve

Geist HJ, Lambin EF (2004) Dynamic causal patterns of desertification. BioScience 54:9. doi:10.1641/0006-3568
GTZ (2009) Running dry? Climate change in drylands and how to cope with it. Oekom Publishers, Munich

Herwig K, Ludi E (1999) The performance of selected soil and water conservation measures-case studies from Ethiopia and Eritrea. Catena 36:99-114

Hilderink HBM, Lucas PL (Eds) (2008) Towards a global integrated sustainability model: GISMO 1.0 status report. Netherlands environmental assessment agency (PBL), Bilthoven

Hinkel J (2009) A framework for analysing methodologies for vulnerability assessments. In: Patt AG, Schröter D, de la VegaLeinert AC, Klein RJT (eds) Environmental vulnerability assessment. Earthscan, London

Hinkel J (2011) Indicators of vulnerability and adaptive capacity: towards a clarification of the science-policy interface. Glob Environ Chang 21:198-208. doi:10.1016/j.gloenvcha.2010.08.002

Hootsman R, Bouwan A, Leemans R, Kreileman GJJ (2001) Modelling land degradation in IMAGE 2. Report 481508009, National Institute for Public Health and the Environment, Bilthoven

Hubert L, Arabie P (1985) Comparing Partitions. J Classif 2:193-218. doi:10.1007/BF01908075

Ifejika Speranza C, Kiteme K, Wiesmann U (2008) Droughts and famines: the underlying factors and the causal links among agropastoral households in semi-arid Makueni district, Kenya. Global Environ Change 18:220-233. doi:10.1016/j.gloenvcha.2007.05.001

Jäger J, Kok MTJ (coordinating lead authors) (2007) Vulnerability of people and the environment: challenges and opportunities, Chapter 7 (pp. 301-360) in Global Environmental Outlook-4. Environment for Development. Earthscan, Nairobi

Janssen P, Walther C, Lüdeke MKB (2012) Cluster analysis to understand socio-ecological systems: a guideline. Potsdam: Potsdam-Institut für Klimafolgenforschung, PIK-Report 126

Kaly U, Pratt C, Mitchell J (2004) Environmental vulnerability index (EVI) 2004. South Pacific Applied Geoscience Commission. http://islands.unep.ch/EVI\%202004\%20Technical\%20Report. pdf

Kasperson RE, Dow K, Archer ERM, Caceres D, Downing TE, Elmqvist T, Eriksen S, Folke C, Han G, Iyengar K, Vogel C, Wilson KA, Ziervogel G, Norgaard R, Rapport D (2005) Vulnerable peoples and places. In: Hassan R, Scholes R, Ash $\mathrm{N}$ (eds) Ecosystems and human well-being: current state and trends, vol 6. Island Press, Washington, pp 143-164

Kassahun A, Snyman HA, Smit GN (2008) Impact of rangeland degradation on the pastoral production systems, livelihoods and perceptions of the Somali pastoralists in Eastern Ethiopia. J Arid Environ 72:1265-1281. doi:10.1016/j.jaridenv.2008.01.002

Klein Goldewijk K, Beusen A, Janssen P (2010) Long-term dynamic modeling of global population and built-up area in a spatially explicit way: HYDE 3.1. Holocene 20:565-573. doi:10.1177/ 0959683609356587

Kok M, Jäger J (2013) Archetypical patterns of vulnerability to environmental change: an approach to bridging scales. Lessons learned from UNEP's fourth global environment outlook. In: Measuring vulnerability to natural hazards. Towards disaster resilient societies. Second Edition. 2013. UNU press

Kok M, Jäger J, Karlsson SI, Ludeke MB, Mohammed-Katerere J, Thomalla F (2009) Vulnerability of people and the environment-challenges and opportunities. Background report on chapter 7 of GEO-4. Report no. 555048002, Netherlands Environmental Assessment Agency (PBL), Bilthoven

Kok MTJ, Lüdeke MKB, Sterzel T, Lucas PL, Walter C, Janssen P, de Soysa I (2010) Quantitative analysis of patterns of vulnerability to global environmental change. Netherlands Environmental Assessment Agency (PBL), Report nr. 550025005, Bilthoven, 2010. http://www.pbl.nl/en/publications/2010/Quantitative-analy sis-patterns-vulnerability-global-environmental-change 
Le Sage A, Majid N (2002) The livelihoods gap: responding to economic dynamics of vulnerability in Somalia. Disasters 26:10-27. doi:10.1111/1467-7717.00188

Locantore NW, Tran LT, O'Neill RV, McKinnis PW, Smith ER, O'Connell M (2004) An overview of data integration methods for regional assessment. Environ Monit Assess 94:249-261. doi:10.1023/B:EMAS.0000016892.67527.4c

Lonergan S, Gustavson K, Harrower M (1999) Mapping human insecurity. In: Lonergan Stephen C (ed) Environmental change, adaptation, and human security. Kluwer Academic Publishers, Amsterdam, pp 397-413

Lüdeke MKB, Petschel-Held G, Schellnhuber HJ (2004) Syndromes of global change: the first panoramic view. GAIA 13(1):42-49

Lüdeke MKB, Walther C, Sterzel T, Kok MTJ, Lucas P, Janssen P, Hilderink H (2014) Understanding change in patterns of vulnerability. Potsdam Institute for Climate Impact Research (PIK) Report 127

MacQueen JB (1967) Some methods for classification and analysis of multivariate observations. Proceedings of 5th Berkeley Symposium on Mathematical Statistics and Probability 1. University of California Press pp 281-297

Manuel-Navarrete D, Gómez JJ, Gallopin G (2007) Syndromes of sustainability of development for assessing coupled humanenvironmental systems vulnerability. The case of hydrometeorological extreme events in Central America and the Caribbean. Glob Environ Change 17(2):207-217. doi:10.1016/j.gloenvcha. 2006.07.002

McCarthy JJ Canziani OF, Leary NA, Dokken DJ, White KS (Eds.) (2001) Climate change 2001: impacts, adaptation, and vulnerability. Contribution of working group II to the Third assessment report of the intergovernmental panel on climate change. Cambridge University Press, Cambridge, UK

Meijer J, Klein Goldewijk K (2009) Global roads inventory project (GRIP). Netherlands Environmental Assessment Agency, Bilthoven, The Netherlands, http://mapserver.mnp.nl/geonetwork

Milligan GW (1980) An examination of the effect of six types of error perturbation on fifteen clustering algorithms. Psychometrika 45:325-342. doi:10.1007/BF02293907

Milligan GW, Cooper MC (1988) A study of standardisation of variables in cluster analysis. J Classif 5:181-204. doi:10.1007/ BF01897163

Misselhorn AA (2005) What drives food insecurity in Southern Africa? A meta-analysis of household economy studies. Glob Environ Change 15(2005):33-43. doi:10.1016/j.gloenvcha.2004.11.003

MNP (2006) Integrated modelling of global environmental change. In: Bouwman AF, Kram T, Klein Goldewijk K (eds) An overview of IMAGE 24. Netherlands Environmental Assessment Agency (MNP), Bilthoven

Mortimore M with contributions from Anderson S, Cotula L, Davies J, Faccer K, Hesse C, Morton J, Nyangena W, Skinner J, Wolfangel C (2009) Dryland opportunities: a new paradigm for people, ecosystems and development, IUCN, Gland, Switzerland; IIED, London, UK and UNDP/DDC, Nairobi, Kenya

Mustafa D, Qazi MU (2007) Transition from Karez to tubewell irrigation: development, modernization, and social capital in Balochistan, Pakistan. World Dev 35(10):1796-1813. doi:10. 1016/j.worlddev.2007.06.002

Neumann K, Sietz D, Hilderink H, Janssen P, Kok M, van Dijk H (2014) Evironmental drivers of human migration in drylands-a spatial picture. Appl Geogr

O'Brien K, Leichenko R, Kelkar U, Venema H, Aandahl G, Tompkins H, Javed A, Bhadwal S, Barg S, Nygaard L, West J (2004) Mapping vulnerability to multiple stressors: climate change and globalization in India. Glob Environ Change 14:303-313. doi:10.1016/j.gloenvcha.2004.01.001
Parry ML, Canziani OF, Palutikof JP, van der Linden PJ, Hanson CE (eds) (2007). Impacts, adaptation and vulnerability. Contribution of working group II to the fourth assessment report of the Intergovernmental Panel on Climate Change. Cambridge University Press, Cambridge

Patt AG, Schröter D, de la Vega-Leinert AC, Klein RJT (2009) Vulnerability research and assessment to support adaptation and mitigation: common themes from the diversity of approaches. In: Patt AG, Schröter D, de la Vega-Leinert AC, Klein RJT (eds) Assessing vulnerability to global environmental change: making research useful for adaptation decision making and policy. Earthscan, London

Petschel-Held G, Block A, Cassel-Gintz M, Kropp J, Lüdeke MKB, Moldenhauer O, Reusswig F, Schellnhuber HJ (1999) Syndromes of Global Change: a qualitative modelling approach to assist global environmental management. Environ Model Assess 4:295-314. doi:10.1023/A:1019080704864

Polsky C, Neff R, Yarnal B (2007) Building comparable global change vulnerability assessments: the vulnerability scoping diagram. Glob Environ Change 17:472-485. doi:10.1016/j. gloenvcha.2007.01.005

Preston BL, Yuen EJ, Westaway RM (2011) Putting vulnerability to climate change on the map: a review of approaches, benefits, and risks. Sustain Sci 6:177-202. doi:10.1007/s11625-011-0129-1

Ram KA, Tsunekawa A, Sahad DK, Miyazaki T (1999) Subdivision and fragmentation of land holdings and their implication in desertification in the Thar Desert, India. J Arid Environ 41:463-477. doi:10.1006/jare.1999.0495

Reynolds JF, Smith D Mark Stafford, Lambin EF, Turner BL II, Mortimore M, Batterbury SPJ, Downing TE, Dowlatabadi H, Fernández RJ, Herrick JE, Huber-Sannwald E, Jiang H, Leemans R, Lynam T, Maestre FT, Ayarza M, Walker B (2007) Global desertification: building a science for dryland development. Science 316:847. doi:10.1126/science. 1131634

Rothman DS, Romero Lankao P, Schweizer V, Bee B (2014) Challenges to adaptation: a fundamental concept for a new generation of socioeconomic scenarios. Clim Change 122:495-507. doi:10.1007/s10584-013-0907-0

Rudel TK (2005) Tropical forests: regional paths of destruction and regeneration in the late 20th Century. Columbia University Press, New York

Rudel TK (2008) Meta-analyses of case studies: a method for studying regional and global environmental change. Glob Environ Change 18(1):18-25. doi:10.1016/j.gloenvcha.2007.06.001

Safriel U, Adeel Z (2008) Development paths of drylands: thresholds and sustainability. Sustain Sci 3:117-123. doi:10.1007/s11625007-0038-5

Safriel U, Adeel Z, Niemeijer D, Puigdefabres J, White R, Lal R, Winslow M, Ziedler J, Prince S, Archer E, King C (2005) Dryland systems. In: Hassan R, Scholes R, Ash N (eds) Ecosystems and human well-being: current state and trends, vol 1. Island Press, Washington, pp 623-662

Sallu SM, Twyman D, Stringer LC (2010) Resilient or vulnerable livelihoods? Assessing livelihood dynamics and trajectories in rural Botswana. Ecol Soc 15:3

Schröter D, Polsky C, Patt A (2005) Assessing vulnerabilities to the effects of global change: an eight step approach. Mitig Adapt Strat Glob Change 10(4):573-595. doi:10.1007/s11027-0056135-9

Shiferaw B, Obare G, Muricho G (2008) Rural market imperfections and the role of institutions in collective action to improve markets for the poor. Nat Res Forum 32(1):25-38. doi:10.1111/j. 1477-8947.2008.00167.x

Siebert S, Feick S, Hoogeveen J (2005) A digital global map of irrigated areas-an update for Asia. Frankfurt Hydrology Paper 
01, Frankfurt University, Frankfurt/M., Germany and Food and Agriculture Organization of the United Nations, Rome, Italy

Sietz D (2014) Regionalisation of global insights into dryland vulnerability: better reflecting smallholders' vulnerability in Northeast Brazil. Glob Environ Change 25:173-185. doi:10. 1016/j.gloenvcha.2014.01.010

Sietz D, Untied B, Walkenhorst O, Lüdeke MKB, Mertins G, Petschel-Held G, Schellnhuber HJ (2006) Smallholder agriculture in Northeast Brazil: assessing heterogeneous human-environmental dynamics. Reg Environ Change 6:132-146. doi:10. 1007/s10113-005-0010-9

Sietz D, Lüdeke MKB, Walther C (2011) Categorisation of typical vulnerability patterns in global drylands. Glob Environ Change 21(2):431-440. doi:10.1016/j.gloenvcha.2010.11.005

Sietz D, Mamani Choque SE, Lüdeke MKB (2012) Typical patterns of smallholder vulnerability to weather extremes with regard to food security in the Peruvian Altiplano. Reg Environ Change 12(3):489-505. doi:10.1007/s10113-011-0246-5

Srinivasan V, Lambin EF, Gorelick SM, Thompson BH, Rozelle S (2012) The nature and causes of the global water crisis: syndromes from a meta-analysis of coupled human-water studies. Water Resour Res. doi:10.1029/2011WR011087

Stehfest E, van Vuuren D, Kram T, Bouwman L, Alkemade R, Bakkenes M, Biemans H, Bouwman A, den Elzen M, Janse J, Lucas P, van Minnen J, Müller M, Prins A (2014) Integrated assessment of global environmental change with IMAGE 3.0. Model description and policy applications, The Hague: PBL Netherlands Environmental Assessment Agency

Sterzel T, Lüdeke MBL, Kok M, Walther C, Sietz D, de Soysa I, Lucas P, Janssen P (2014) Armed conflict distribution in global drylands through the lens of a typology of socio-ecological vulnerability. Reg Environ Change 1-17

Thomas RJ (2008) Opportunities to reduce the vulnerability of dryland farmers in Central and West Asia and North Africa to climate change. Agric Ecosyst Environ 126(1-2):36-45. doi:10. 1016/j.agee.2008.01.011
Tschakert P (2007) Views from the vulnerable: understanding climatic and other stressors in the Sahel. Glob Environ Change 17(2007):381-396. doi:10.1016/j.gloenvcha.2006.11.008

Turner BL, Kasperson RE, Matson PA, McCarthy JJ, Corell RW, Christensen L, Eckley N, Kasperson JX, Luers A, Martello ML, Polsky C, Pulsipher A, Schiller A (2003) A framework for vulnerability analysis in sustainability science. PNAS 100(14):8074-8079. doi:10.1073/pnas.1231335100

Twomlow S, Riches C, O’Neill D, Brookes P, Ellis-Jones J (1999) Sustainable dryland smallholder farming in sub-Saharan Africa. Ann Arid Zone 38(2):93-135

UNEP (2007) Global environmental outlook IV. United Nations Environmental Programme, EarthScan, London

UNSTAT (2005) national accounts main aggregates database. United Nations Statistics Division

Vogel C, O'Brien K (2004) Vulnerability and global environmental change: rhetoric and reality. AVISO 13:1-8

Ward JH (1963) Hierarchical grouping to optimize an objective function. J Am Stat Assoc 58:36-244

WBGU (1995) World in transition: The threat to soils. Annual report of the German Advisory Council on Global Change (WBGU), Bonn: Economica Verlag

Welle T, Birkmann J, Kruse D, Suarez DC, Setiadi NJ, Wolfertz J (2013) The WorldRiskIndex: a concept for the assessment of risk and vulnerability at global/national scales. Chapter 9 in: measuring vulnerability to natural hazards. Towards disaster resilient societies. Second Edition. 2013. UNU press

Wolf S, Hinkel J, Hofmann M, Bisaro A, Lincke D, Ionescu C, Klein RJT (2012) Clarifying vulnerability definitions and assessments using formalisation. Int $\mathrm{J}$ Clim Change Strateg Manag 5(1):54-70. doi:10.1002/wcc.314

World Bank (2006) World Development Indicators. World Bank, Washington DC, www.worldbank.org/data, www.worldbank. org/data 